\title{
How Do Large Companies Manage Their Investments Across the Three Horizons? \\ Peter Carbone
}

\author{
(6 It is relatively easy to do product management, or to manage"s \\ research on future products. A good general manager needs \\ to be able to manage both at the same time.
}

A Nortel executive

Circa 2007

\begin{abstract}
Technical entrepreneurship continues to be important to a technology company's health and growth, even after it has successfully delivered its first product. It is essential to help the company deal with competitive forces and to renew its revenue stream. However, as the company grows, its entrepreneurial capability often becomes handicapped both by company culture as well as external pressures. The company must achieve the right mix of investment and level of attention across three time horizons of growth: immediate, imminent, and future. This balancing act requires a commitment to a strategic growth goal, appropriate tools, and leaders that can manage significant degrees of uniqueness in the resources that address each of these time horizons.
\end{abstract}

This article discusses some of the horizon-management challenges faced by top management teams of large companies and overviews some mechanisms and processes that have worked effectively. Large companies must overcome internal teams' divergent values and culture as well as significant external, short-term pressures being applied by their existing base of customers and markets. Discipline at the entry point to Horizon 3 (exploratory phase) and then a rapid transition to Horizon 1 (current operations) is the priority of any successful growth company.

\section{Introduction}

All companies are eventually faced with the reality that sustained growth can only come from continuous innovation. Changes in customer needs, competitive offers, and breakthrough opportunities all require a constant flow of ideas to cash. The "three horizons model" has been used to characterize the relative business maturity of investment, with Horizon 1 (H1) being focused on existing business, Horizon 2 (H2) on emerging business, and Horizon 3 (H3) on options for future business (Baghai et al., 2000; tinyurl.com/87bfmtu). It would seem quite straightforward to balance investments across the three horizons to ensure a continuous flow of innovation; however, many companies experience significant difficulty investing in the future. In this article, we will explore some of the more significant challenges in managing each of the horizons within a large company and we will discuss some approaches that have been successful. Bell-Northern Research (BNR; tinyurl.com/6vrpyt3) and Nortel (tinyurl.com/24gm7a) were well known for successful innovation management, in particular prior to the dot-com bubble (c. 2000), and provide examples of how to address such challenges.

The skills, values, and effort required to address each horizon are fundamentally different, making collaboration between the respective teams and transitioning between horizons challenging. Table 1 summarizes some of the characteristics that impact investment decisions associated with each horizon.

Horizon 1 is the primary focus for the majority of the company because it deals with existing portfolios and customers and because it consumes most of their resources. H1 management tends to be very operational 


\section{How Do Large Companies Manage Their Investments Across the Three Horizons?}

Peter Carbone

Table 1. Summary of horizon characteristics impacting investment

\begin{tabular}{|c|c|c|}
\hline Horizon & Description & Characteristics impacting investment \\
\hline H1. Immediate impact & $\begin{array}{l}\text { Farming } \\
\text { - Current business portfolio }\end{array}$ & $\begin{array}{l}\text { - Customer driven (e.g., feature requests) } \\
\text { - Competitor driven (e.g., to respond to an } \\
\text { attack) } \\
\text { - Cost driven (e.g., for continuous improvement) } \\
\text { - Investor driven (e.g., stock price) } \\
\text { - Rarely innovation driven (except supply chain } \\
\text { process, e.g., Dell) }\end{array}$ \\
\hline H2. Short-term impact & $\begin{array}{l}\text { Hunting } \\
\text { - New portfolio or portfolio } \\
\text { elements } \\
\text { - New customers/segments }\end{array}$ & $\begin{array}{l}\text { - Lead-customer driven (e.g., triggers } \\
\text { deployment) } \\
\text { - First-to-market driven (e.g., Apple, RIM) } \\
\text { - Cost or feature differentiation } \\
\text { - Time urgency (e.g., time to market) } \\
\text { - New entry may involve mergers or acquisitions } \\
\text { for time or feature advantage }\end{array}$ \\
\hline
\end{tabular}

\begin{tabular}{|c|c|}
\hline H3. Long-term impact & $\begin{array}{l}\text { Exploring } \\
\text { - Exploring potential new } \\
\text { business opportunities } \\
\text { - looking for "the next big thing" }\end{array}$ \\
\hline
\end{tabular}

- Strategy driven (e.g., to support company direction)

- Talent driven (e.g., constrained/enabled by what the people can do, visionaries)

- Differentiation driven (e.g., "the next big thing")

- Impact driven (e.g., "the art of the possible")

- Tested outside of market (e.g., low cost)

and features traditional cost and profitability metrics. Horizon 2 is more entrepreneurial because it often deals with the introduction and development of new portfolios along with potential innovation for bringing these offers to new customers or markets. H2 initiatives often have only revenue or customer growth metrics. Horizon 3 is the highest risk and is often at odds with other company activities (e.g. it may obsolete an existing portfolio). $\mathrm{H} 3$ initiative metrics may be less tangible and include things such as supporting the brand, securing patents, and creating industry leadership. Product managers champion $\mathrm{H} 1$ initiatives, and researchers in $\mathrm{R} \& \mathrm{D}$ champion $\mathrm{H} 3$ initiatives. H2 initiatives are harder to resource, requiring operational leaders to take decisions as well as execution risks.

\section{Managing Investment Challenges}

Companies face complex challenges as they attempt to continuously renew their value proposition while defending current business. There are (at least) three fundamental aspects that impact a company's decision process regarding horizon program management.
Strategy (shifting focus beyond H1 to leverage H2/H3) The big challenges in $\mathrm{Hl}$ are dealing with momentum (proactively shifting to something new) and prioritization (of large successful portfolios). Strong founders that have personal strategy objectives and a unique ability to drive execution enable companies to more easily balance investment across horizons. Examples include Bill Gates' decision to address the internet opportunity or Steve Jobs launching into a new smartphone market segment). However, most companies must use a top-down strategy to overcome short-term pressures, to resolve conflicts and facilitate re-prioritization of H2/H3. They can become distracted by the success (or failing) of current business and pay little attention to strategy beyond the next one or two quarters. Challenges that make it difficult for the CEO to ensure sufficient attention is paid to executing strategy decisions include management-by-committee approaches, internal conflicts resulting from divergent or competing portfolio elements or market offers (e.g., smaller, inexpensive switches for enterprises versus higher-capacity, redundant switches for carriers), or a lack of talent/investment to be able to "add anything 


\section{How Do Large Companies Manage Their Investments Across the Three Horizons?}

Peter Carbone

new". Investment tagged as $\mathrm{H} 2$ or $\mathrm{H} 3$ has been found to be applied to feature development or incremental product evolution for current programs. For example, after the decision was made to absorb Nortel's research arm (BNR) into the respective lines of business, BNR's dedicated focus on "inventing the future", based on technical merit/breakthroughs and technical management was quickly displaced by a focus on low-risk, short-term, current-customer-driven business opportunities.

\section{External forces (facts of life)}

External forces place significant pressure on any company, but large public ones are particularly susceptible because they need to balance company/customer benefits. Also, to tradeoff short and medium/longer-term benefits requires effort to offset the natural focus on $\mathrm{H} 1$. The two largest sources of pressure are the investors and the customers. Investors are very focused on return and do drive the behaviour of a company. In the recent case of Research in Motion (RIM), investors drove a leadership change due to the perception of unfavorable results. In all cases, investors drive an operational focus with ongoing scrutiny of the company's finances (i.e., profit, costs, growth). This empowers $\mathrm{Hl}$ teams, the largest population of a company, to drive investment decisions, often at the expense of $\mathrm{H} 2 / \mathrm{H} 3$ initiatives. The tactic of buying technology/companies further handicaps internal H2/H3 initiatives.

Customers may also be a major force towards $\mathrm{H} 1$ investment. Nortel had large customers who wanted to "strategically partner" with them to drive differentiated solutions (e.g., to develop custom features or specific standards development, or to influence the timing of technology deployment in their favour). These customers would gladly consume all of the R\&D investment and development cycles to support their short-term strategies and it was very difficult to decline requests from these large, profitable customers in favour of making future bets.

\section{Culture, motivation, and incentive}

The culture of a company is reflected in its employee values and impacts the company's overall ability to rapidly create cross-horizon teams required to bring a flow of innovation to the market. In a company with significant customer interaction and $\mathrm{Hl}$ focus, there is little incentive to take risks on futures, so measurable targets and incentives to take on new things becomes mandatory to legitimize $\mathrm{H} 2 / \mathrm{H} 3$ programs and attract the talent required to deliver them. The reward system in most companies focuses on hitting sales targets, cost-reduction targets, or market-share targets. Successful general managers argue for incremental investment on their "sure thing" initiative versus wasting money speculating on something that was very high risk. In the early days, Nortel's Optical Network division (in the H2 stage) was losing money while racing to bring some breakthrough 10G technology to market. The switching team had many customer feature requests to satisfy and made the argument to starve the $\mathrm{H} 2$ program in favour of guaranteed $\mathrm{H} 1$ revenue.

\section{Horizon Management Approaches}

There are mechanisms that have been successfully used to balance investment across the horizons, manage within the horizons, and then manage transitions from H3 to H1. Below, we explore some of the mechanisms that have succeeded.

\section{Managing H1 (farming)}

All companies have processes to manage their market offer. Large companies have the following additional complexities: large and complex portfolios that compete for resources (e.g., Nortel played in 13 distinct segments); significant customers demanding attention (e.g., large Regional Bell Operating Companies had significant value-chain power due to their volume purchases); self-serving internal momentum and zeal for internal programs; and competition between portfolios (e.g. optical versus switching), making collaboration difficult.

To coordinate investment and execute top-down strategy, Nortel implemented a Portfolio Review Board to provide overall portfolio-management direction and investment allocation. It consisted of senior executives with accountability for results at a portfolio level (e.g. business unit presidents, CTO, CEO) and was led by the CTO as an impartial chair. The activities of the Portfolio Review Board were to:

1. Benchmark the portfolio objectively against the industry in terms of market share, sector growth, and competitive position. Key to doing this properly was to separate internally bundled portfolio elements to explicitly eliminate cross-subsidization that masked overall performance. In the case of the wireless portfolio, separating the profitable CDMA business from the unprofitable UMTS business facilitated appropriate decision making. This approach proved insightful to the executive team in that they gained a realistic, objective view of 


\section{How Do Large Companies Manage Their Investments Across the Three Horizons?}

Peter Carbone

current business realities, which helped them to decide to exit small and less profitable segments and to deal more aggressively with portfolios that were dragging down the whole company.

2. Assess opportunities to enhance the portfolio performance (e.g., cost reduction potential, platform potential) with the objective to maximize the success of the portfolio. A more internally focused portfolio assessment explored revenue contribution, profitability, $R \& D$ efficiency/affordability, customer-revenue upside of changing investment profiles, and competitive impacts. This step identified the "stars and the dogs" of the portfolio.

3. Obtain feedback on any business impacts of changes (e.g., customer or competitor implications, internal portfolio cross-impacts, sale of asset value potential). This step identified potential external constraints on actions (e.g., in one case it resulted in decisions to sell businesses/products versus terminate them to protect existing customers). Product managers were consulted with an objective of minimizing surprises and starting the buy-in process for the changes. Since a larger group of people were now aware of the decision process and options, extra care was needed at this stage to prevent rumours from undermining decisions (e.g., key employees leaving, leaked intentions of sale impacting customer deals or portfolio valuation).

4. Implement decisions taken at the review board to increase or decrease investment, terminate programs, sell portfolio elements, etc. These decisions had to be executed quickly and efficiently. A senior executive was assigned the job of executing the decision, in many cases the president of a business unit. Small teams were assembled to assist in rapid execution. At this stage, care was needed to minimize the potential for disgruntled-employee actions that could undermine the business strategy (e.g., leaking plans to the market, creating customer confusion by positioning alternatives to the agreed strategy). Employees negatively impacted by the decision (e.g., who lose their job or lose status) needed to be engaged to avoid "misadventure".

A small, dedicated team of analysts were assigned to provide market data, run scenarios to provide decision data, and run the Portfolio Review Board process. This team was independent of the various product groups and had to overcome the business unit's reluctance to surrender their total control over this corporate data. CEO and CFO support was required to ensure appropriate and timely information was available. This was done by the CEO participating in Portfolio Review Board meetings, and having the line-of-business presidents actively engaged in identifying and evaluating outcomes.

\section{Managing H2 (hunting)}

Managing emerging opportunities is often a challenge because it demands substantial investment in advance of securing revenue, and there may not be an internal champion at the executive or middle-management level willing to assume the risk. Additionally, H2 initiatives often are harassed by larger, successful programs for money (e.g. the optical versus switching scenario described earlier). These initiatives required empowered, senior executives to make the change and provide the opportunity for ambitious rising managers to shine. Nortel has numerous examples of extraordinary efforts required to launch $\mathrm{H} 2$ initiatives successfully. In one case, the CEO sent in a senior operational executive to trim the switching portfolio in order to fund the optical portfolio development. In another case, the CEO, concerned about the company's dependence on a single portfolio (switching), made the decision to enter a new space (wireless). In both cases, the new portfolio grew to eclipse the incumbent portfolio, but could not have happened without executive intervention at the highest level. What is unique about a large company is that competition is often both external and internal, with internal competition needing explicit attention.

Factors that contributed to the success of $\mathrm{H} 2$ programs included:

- senior executive support, both in providing required financial and people resources, but also attracting talent to lead the H2 program. In some cases, this approach required special direct reporting to protect the unit and promotion incentives on successful outcomes to secure the right leaders.

- rapid growth (according to approved plan) for a new initiative (i.e., it needs to become big enough, fast enough to matter)

- conscious decisions to re-prioritize current programs and to provide affected teams with the support required to implement the plan. 


\section{How Do Large Companies Manage Their Investments Across the Three Horizons?}

\section{Peter Carbone}

\section{Managing H3 (exploring)}

The spirit behind the investments in $\mathrm{H} 3$ is to renew the business and focus on the future, as opposed to evolving the present. To assure the integrity of the H3 funnel, it is necessary to establish explicit criteria that are used to determine $\mathrm{H} 1$ versus $\mathrm{H} 3$ opportunities. Table 2 provides some criteria that may be used for this purpose.

In order for H3 programs to be successful, different tactics have been used to overcome the natural risk aversion and momentum of $\mathrm{H} 1$ initiatives:

- CEO review of each horizon's programs separately, which placed peer pressure on executives (did not want to expose any lack of focus on the future).

- Setting strategic targets for investment for each horizon (for example $20 \%-60 \%-20 \%$ for $\mathrm{H} 1-\mathrm{H} 2-\mathrm{H} 3 \mathrm{R} \& \mathrm{D}$ investment) to reflect the strategic intent to invest in the future. This shifted the discussion from "what are you wasting money on", to the more constructive "what am I getting for my $20 \%$ ?"

- Introduction of an executive incentive that required the unit to deliver a defined percentage of revenue from new products released in the last 12-18 months. In the
Nortel case described earlier, a strong executive leader tasked to support implementation of a corporate strategy (Fiberworld) intervened and shifted investment to support the emerging optical business, which ultimately grew to eclipse the switching business. Although there is always some gaming of the system and debate around definitions, one can shift investment and executive attention more towards $\mathrm{H} 2$ and $\mathrm{H} 3$ initiatives.

Two successful examples of H3 investment management were BNR's Capability Program and Nortel's Advanced Technology Program, both of which explored breakthrough domains. Both programs were structured similarly in a number of areas:

- An annual budget and full-time researchers provided the required continuity over years, which was necessary to identify and develop breakthroughs.

- The programs were reviewed by business executives but were managed by technical R\&D executives/fellows.

- They provided a focal point for university research programs to ensure currency of research, to secure complementary insights from experts around the world, and to handle high-risk, disruptive investigation as insurance for potential disruption of internal programs.

Table 2. Horizon 3 criteria versus H1 criteria

\begin{tabular}{|c|c|c|}
\hline Criteria & Considered for H3 Prioritization & Referred to Portfolio (H1) \\
\hline Timing & $\begin{array}{l}\text { - } 18-36 \text { months for commercialization } \\
\text { - Disruptive to current business in shorter } \\
\text { time/decision risk }\end{array}$ & $\begin{array}{l}\text { - Within 1-2 releases of current portfolio } \\
\text { - Implementation risk }\end{array}$ \\
\hline Disruption/New & $\begin{array}{l}\text { - Not currently addressed by portfolio } \\
\text { (technology, solution, business model) } \\
\text { - Competitive with current portfolio } \\
\text { - Not addressed in the market } \\
\text { - Unknown potential, maturity, technical } \\
\text { viability }\end{array}$ & $\begin{array}{l}\text { - Portfolio extension } \\
\text { - Mandated by standards for evolution } \\
\text { - Not separable business from portfolio } \\
\text { - Required for existing business success } \\
\text { - Sustaining technology investment }\end{array}$ \\
\hline Capacity & $\begin{array}{l}\text { - Have required competence/skills to assess } \\
\text { - Meaningful effort within budget }\end{array}$ & $\begin{array}{l}\text { - Productization levels of investment } \\
\text { - External sourcing known path forward }\end{array}$ \\
\hline Leadership & $\begin{array}{l}\text { - Program leader dedicated; team identified } \\
\text { and available } \\
\text { - Full-time program and resource } \\
\text { commitment } \\
\text { - Clear exit criteria; monetization plan } \\
\text { - Project plan }\end{array}$ & $\begin{array}{l}\text { - Incremental to current business } \\
\text { - Standards implementation }\end{array}$ \\
\hline
\end{tabular}




\section{How Do Large Companies Manage Their Investments Across the Three Horizons?}

Peter Carbone

- The small-but-stable budgets protected the initiatives from business perturbations; researchers spent their cycles on technical work rather than concerns over their jobs.

- Both programs were aligned and sponsored by business units, which facilitated the transition to $\mathrm{H} 2$.

- A core set of programs were exposed to customers for validation to demonstrate their synergy with the current portfolio and the suitability of their reach.

- The programs featured a "people exchange" between research and line programs. In some cases, researchers would transition with their program to a line R\&D team to bring it to market and then return once it was delivered.

- Both programs were led by visionary researchers that participated in the business. The research executive (VP and СТO) participated in the business reviews of the business units to familiarize themselves with the strategy and needs of the business/customers, and, based on their unique perspective on technology, to offer advanced-technology solutions for the issues identified.

The BNR Capability program was sponsored by the President of BNR and operated by the Technology VP's who were aligned to the business units. This program executed a portion of the annual technology strategic plan. In addition to customer demonstrations of technology, strategy sessions focused on futures were held with key business leaders to expose them to new capability and to garner feedback on research.

Nortel's Advanced Technology Program developed a formal process for admitting initiatives into the funnel and for developing them through the funnel. There was a formal set of (patented) criteria that included focusing on market value, competitive value, viability/affordability, and timing. There was a relevance check only at the beginning, but the weighting of business criteria increased as the initiative was developed and required additional development investment.

\section{Transitioning Between Horizons}

Given the zero-sum budget of most companies, transitioning between horizons requires re-prioritization of existing programs, freeing of key resources, introduction of new players and processes, team building, shifting accountabilities, etc. In the author's experience, this transition proved to be one of the most difficult things to do, as it required a number of people to take on new risks, managing the general manager's fear about impeding sales while customers wait for new portfolio, shifting program culture from research to delivery, and introduction/innovation around new delivery processes.

Success was largely affected by how quickly a transition could be made versus how much money was being spent in $\mathrm{H} 2$ or $\mathrm{H} 3$. The ability to rapidly transition from $\mathrm{H} 3$ to $\mathrm{H} 1$ required the company to respect and support the unique management in each horizon and to link the processes across a portfolio lifecycle.

\section{Conclusion}

Managing a scarce resource like investment is challenging for any company, however large companies have to address the additional complexities of satisfying current customers during a change, shifting internal momentum and priorities, as well as nurturing new initiatives during difficult market challenges. To manage across horizons, executive leadership must visibly and tangibly enable and support it. Managing across horizons requires large companies to:

- develop and execute a strategy to overcome distractions, to align teams, and to facilitate re-prioritization of existing programs

- make decisions based on accurate data on business performance

- establish and receive buy-in for clear targets for investments and results on a per-horizon basis

- assign strong leaders to champion initiatives (i.e., take decision and execution risks) and to manage across a diverse set of skills

- explicitly overcome $\mathrm{H} 1$ inertia 


\title{
How Do Large Companies Manage Their Investments Across the Three Horizons?
}

Peter Carbone

\begin{abstract}
About the Author
Peter Carbone is a successful executive known for his thought leadership, business acumen, and technology leadership. He is often called on to address new business and technology challenges. Peter is a pathfinder with a track record of creating innovative solutions, strategically managing technology and innovation, successfully launching and running new businesses, and leading business development initiatives. Peter has held CTO, R\&D, and senior business positions in several high-tech companies, and he has led or been directly involved with several technology company acquisitions. Peter has been engaged as technical advisor to startups, is part of the faculty of an entrepreneur development program that has created $>100$ new companies, and has been on the boards of US-based Alliance for Telecommunications Industry Solutions (ATIS) and Coral CEA. He is past Vice-Chair of the Executive Committee of the Information Technology Association of Canada (ITAC) and Chair of an ITAC committee, which is focused on the Global Competitiveness of Canada's Knowledge Economy. Peter is also on the Advisory Board of the Technology Innovation Management Review.
\end{abstract}

